\title{
Quantitative study of impacts of climate change and human activities on runoff in Beiluohe River basin
}

\author{
AIJUN GUO, QIANG HUANG \& YIMIN WANG \\ State Key Laboratory Base of Eco-Hydraulic in Arid Area, Xi'an University of Technology, Jinhua Road 5, Xi'an, \\ Shaanxi, China \\ 634003497@qq.com
}

\begin{abstract}
In the Beiluohe River basin (BRB) runoff has been experiencing a significant reduction induced by climate change and human activities. This paper considers the impacts of climate change and human activities on runoff reduction. An improved empirical method for climate factors and runoff was developed to study the impacts quantitatively. Meanwhile climate elasticity of runoff, based on the Budyko hypothesis, was also adopted to study the impacts. Using runoff change points, series were divided into natural period (1960-1969) and impacted periods (1970-1994, 1995-2010). Results show that the methods used to quantify the contributions obtained different but close conclusions to one another. For 1970-1994, climate was the primary factor impacting runoff, compared with that for 1960-1969, with the contribution reaching around 70.84-83.42\%, which was greater than human activities (16.58-29.16\%). For 1995-2010, the role of human activities strengthened with the contribution around $62.58-65.07 \%$, greater than climate changes, around $34.93-37.42 \%$.
\end{abstract}

Key words the Beiluohe River Basin; climate effect; human activities effect; quantifying the impacts

\section{INTRODUCTION}

Much research on global environmental change and the response to human activities have been done in recent years (Zhang et al., 2007; Bao et al. 2012), showing that environmental changes were mainly caused by climate change and human activities (Milliman et al. 2008; Liquete et al. 2009). With these studies, climate change, mainly precipitation and PE, and human activities including large-scale changes of underlying surface and water consumption and so on, were considered as the main factors impacting the runoff reduction.

In many regions of China, studies on the response of climate change and human activities to runoff change have been running in recent years. For example, the Yellow River, which is second largest river in China and a major source of freshwater for approximately 107 million people within the river basin, is facing a severe shortage of water resource. Studies by Liu and Cui (2011) and $\mathrm{Du}$ and Shi (2012) illustrated that human activities, particularly building of water conservation measures and increased water diversions, etc., were the primary factor influencing the hydrological cycle.

This study focused on Beiluohe River basin and, from various perspectives, assessed the impacts of climate change and human activities on runoff reduction quantitatively. The objectives are: (i) to detect the change points of runoff, precipitation and PE for 1960-2010; (ii) to explore the relationship between annual runoff, precipitation and PE; and (iii) to quantitatively assess the contribution rate from climate change and human activities to runoff by two methods.

\section{STUDY AREA}

The BRB $\left(107^{\circ} 32^{\prime}-110^{\circ} 11^{\prime} \mathrm{E}, 34^{\circ}-37^{\circ} 19^{\prime} \mathrm{N}\right)$ is the second largest tributary of the Yellow River with a total length of $680 \mathrm{~km}$ and drainage area of $26900 \mathrm{~km}^{2}$ (Fig.1). It originates from Dingbian country of Shaanxi Province, which flows through Wuqi, Zhidan, etc., into the Weihe River in the southeast of Dali country. Annual precipitation is $510-540 \mathrm{~mm}$, mainly focused on July and September, and generally deficient in spring and summer; $60 \%$ of precipitation falls between June and October. Annual temperature is $7.87-10.6^{\circ} \mathrm{C}$ and extreme maximum and minimum temperatures are observed in July and January, reaching $39.9^{\circ} \mathrm{C}$ and $-24^{\circ} \mathrm{C}$, respectively. The average annual natural runoff is 6.04 billion $\mathrm{m}^{3}$. In 2010 , total population was 4.27 million and the density of population reached 158 people per $\mathrm{km}^{2}$. 


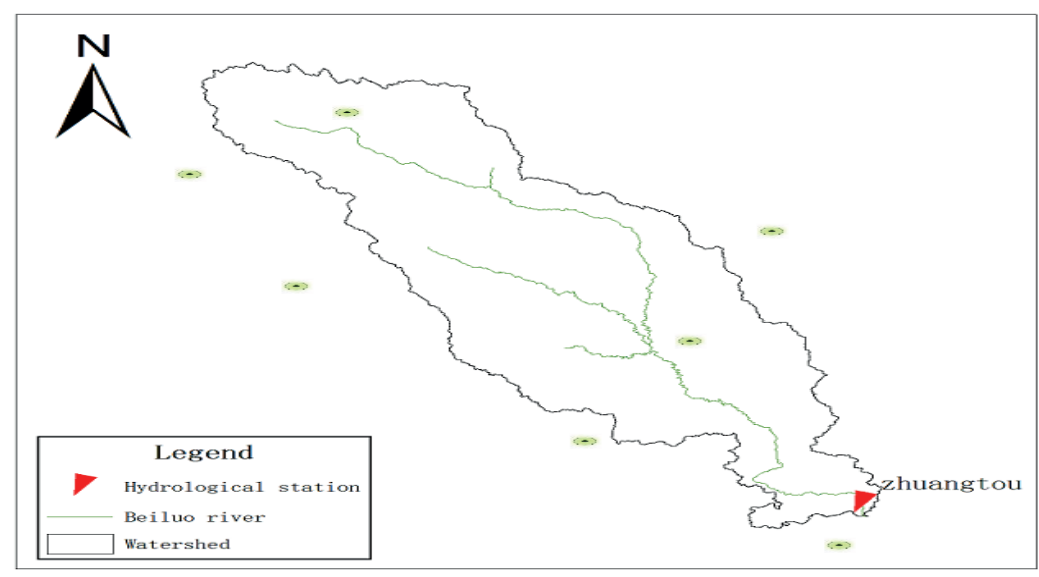

Fig. 1 Locations of the hydrological station and seven meteorological stations in and around BRB.

\section{DATASET AND METHODOLOGY}

\subsection{Dataset}

Monthly and yearly runoff series (1960-2010) from gauging station Zhuangtou, representing the whole basin, were collected from the hydrological year book in the Beiluohe River basin (Fig. 1). The meteorological data (1960-2010) of seven meteorological stations (Fig. 1) within and outside the $\mathrm{BRB}$, including daily precipitation, temperature, wind velocity and sunshine duration, were provided by China Meteorological Data Sharing Service System (http://cdc.cma.gov.cn). By using the meteorological elements of each station, PE was estimated by the FAO Penman-Monteith method. Based on annual precipitation and PE from individual station, and using an ArcGIS platform, annual precipitation and PE for the whole catchment were calculated by the Thiessen polygon method.

\subsection{Methodology}

Sequential cluster analysis was applied to analyse the position of change points in the hydrological series. Two methods, including an improved empirical model of precipitation, PE, runoff and climate elasticity of runoff based on the Budyko hypothesis, and the decomposition method, were applied to quantitatively calculate the contribution rate from climate change and human activities to runoff.

3.2.1 Improved empirical model of precipitation, PE and runoff Runoff, precipitation and evapotranspiration are three major links in the process of the hydrological cycle, which determines global water balance. The empirical model, proposed by Li et al. (2007) and Parks and Madison (1985), only take precipitation as the climate influence factor. In this study, an improved empirical model considering precipitation and $\mathrm{PE}$ was proposed to simulate runoff:

$$
Q_{k}=a\left(\frac{P_{k}}{P E_{k}}\right)^{b}+c
$$

where $Q$ is runoff, $P$ and $P E$ are precipitation and potential evapotranspiration, $k$ means the $k$ th year of runoff, precipitation and potential evapotranspiration. Variables $a, b$ and $c$ are coefficients which are estimated by employing runoff, precipitation and PE in the natural period. Keeping the variables the same and applying precipitation and PE in the impacted period in equation (1), the simulated runoff $Q_{\text {sim }}$ is calculated. The simulated runoff $Q_{\text {sim }}$ in the impacted period can be considered to include the change in climate for the impacted period while retaining the human impact from the natural period. The difference in the observed runoff and the simulated runoff will then yield the contribution from human activities during the impacted period.

The impacts of climate and human activities on runoff can be assessed using equations (2), (3) and (4): 


$$
\begin{aligned}
& C_{c}=\frac{\Delta Q_{C}}{\Delta Q} \times 100 \%=\frac{\left|\overline{Q_{\text {slm }}}-\overline{Q_{\text {nat }}}\right|}{\Delta Q} \times 100 \% \\
& C_{H}=\frac{\Delta Q_{H}}{\Delta Q} \times 100 \%=\frac{\left|\overline{Q_{\text {sim }}}-\overline{Q_{\text {lmp }}}\right|}{\Delta Q} \times 100 \% \\
& \Delta Q=\Delta Q_{C}+\Delta Q_{H}
\end{aligned}
$$

where $C_{c}$ and $C_{H}$ represent the impact of climate change and human activities, $\Delta Q_{C}$ and $\Delta Q_{H}$ represent the average change in runoff induced by climate change and human activities, $\overline{Q_{s l m}}$ and $\overline{Q_{l m p}}$ represent the average simulated and observed runoff during the impacted period, and $\overline{Q_{n a t}}$ represents the average runoff during the natural period.

3.2.2 Climate elasticity of runoff increment based on Budyko hypothesis It is considered that before and after the change point the mean annual average runoff are $Q_{o b s, 1}$ and $Q_{o b s, 2}$ and the increment of runoff affected by climate change and human activities expressed as $\Delta Q_{C}=$ $\varepsilon_{P} \frac{\Delta P}{P} Q+\varepsilon_{P E} \frac{\Delta P E}{P E} Q$ where $\varepsilon_{P}$ and $\varepsilon_{P E}$ are precipitation and PE elasticity of runoff respectively, which can be presented as:

$$
\begin{aligned}
& \varepsilon_{P}=\rho_{Q, P E-P}\left(\frac{C V_{Q}}{C V_{P}}\right) \\
& \varepsilon_{P E}=\rho_{Q, P-P E}\left(\frac{C V_{Q}}{C V_{P E}}\right)
\end{aligned}
$$

where $\rho_{Q, P E-P}$ and $\rho_{Q, P-P E}$ are the partial correlation coefficient of precipitation and potential evaporation with runoff, and $C V_{Q}, C V_{P}$ and $C V_{P E}$ are the coefficients of variation of runoff, precipitation and PE separately. The contribution rate from climate change and human activities to runoff (Liu and Cui, 2011) after the change point compared to that before the change point can be expressed as:

$$
C_{C}=\frac{\left(\varepsilon_{P} \frac{\Delta P}{P}+\varepsilon_{P E} \frac{\Delta P E}{P E}\right) Q}{\Delta Q} \times 100 \%, \quad C_{H}=1-C_{c}
$$

\section{RESULTS}

\subsection{Variation characteristics of runoff and climatic elements}

The method of sequential cluster analysis was employed to detect the change points of annual runoff, precipitation and PE, which are presented in Fig. 2 (a)-(c). There are local minima in 1969 and 1994 on annual runoff, in 1964 and 1985 on annual precipitation and in 1993 on annual PE. The detection result was similar to the research of Dong et al. (2014). The location of the change points on precipitation and PE were close to that on runoff, which may indicate that climate change should be assumed partly responsible for the variation of runoff.

\subsection{Change of relationship between annual runoff and precipitation}

To obtain the relationship of runoff, precipitation and PE, the moving 3-year average method was applied. Figure 3 shows the anomaly of the 3-year moving average series. During 1960-1994, the changes of peaks and valleys in precipitation, PE and runoff were almost simultaneous. However, since 1993, which was same with change of change point of runoff, the changes of peaks and valleys were diffuse and dispersed.

Associated with these changes of change points we found that the 1969 change point of runoff was mainly induced by the change of precipitation, which did not induce the change of relationship between runoff and climate variables. Also, the 1993 change point was maybe caused by $\mathrm{PE}$ and human activities.

To quantify the impacts of climate change and human activities accurately, the change points of runoff, precipitation and PE and the change of relationship between them were considered by dividing the hydrological time series into three epochs: natural period (1960-1969), and impacted periods (1970-1994 and 1995-2010). 

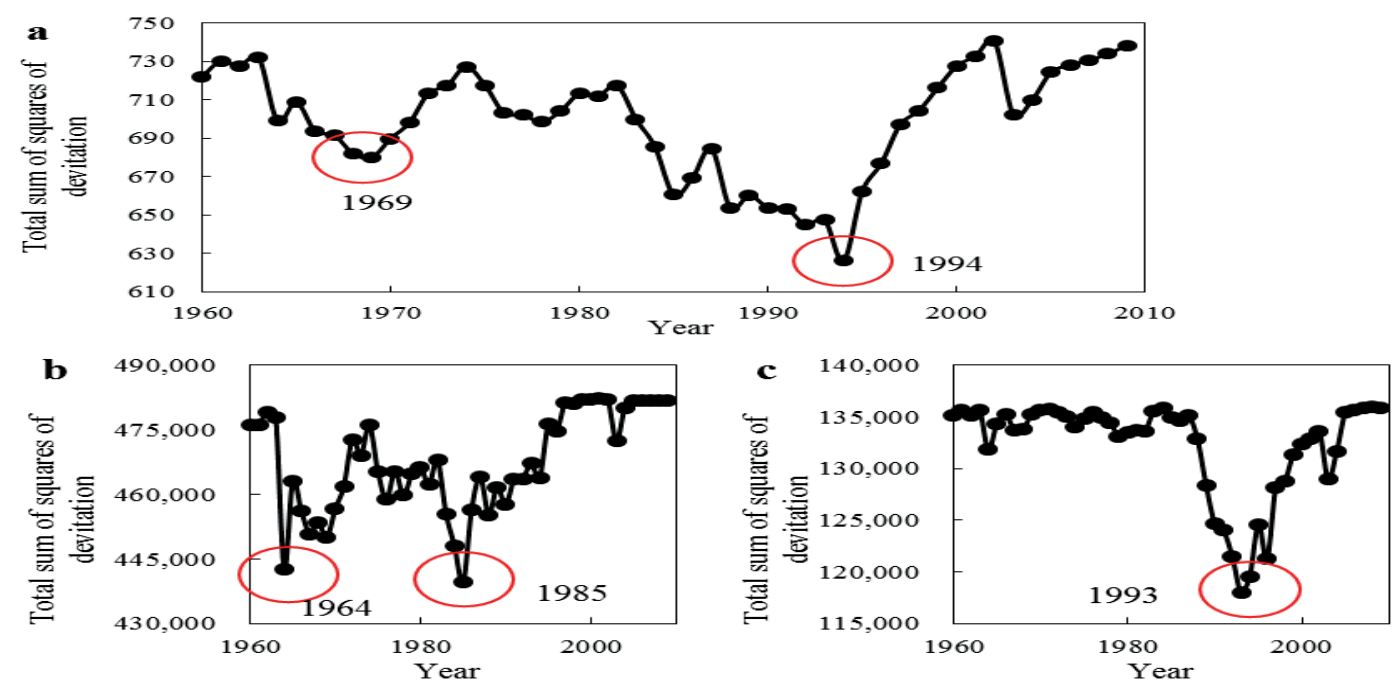

Fig. 2 The change points in the Beiluohe River basin: (a) runoff, (b) precipitation, and (c) PE.

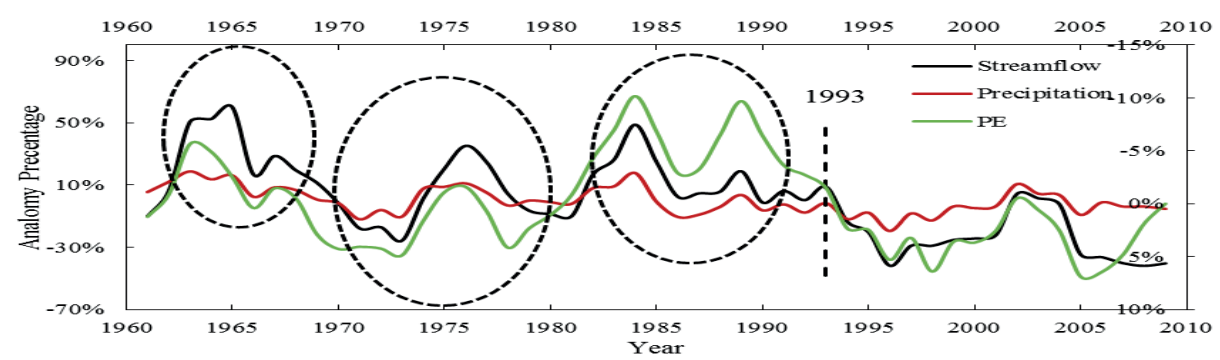

Fig. 3 The change of trend between runoff, precipitation and PE in Beiluohe River basin.

\subsection{Contribution rate of climate change and human activities to the runoff change}

4.3.1 Empirical model of precipitation, $P E$ and runoff Equation (1) was used to simulate the hydrology in the study area and the simulated and observed runoff are presented in Fig. 4. The Nash Sutcliffe coefficient and correlation coefficient reached 0.84 and 0.84 , respectively which illustrates the superior applicability of the empirical model for the study area. The parameters of the empirical model, $a, b$ and $c$, were $9.05,3.75$ and 9.12 respectively.

The contributions from climate change and human activities are listed in Table 1. For 19701994, climate change was the primary influence factor affecting the runoff and the contributions reached $83.42 \%$ and in the second period (1995-2010) the role of human activities strengthened with the contribution rate reaching to $62.58 \%$. The change of climate had a weaker influence on the runoff change than human activities for 1995-2010.

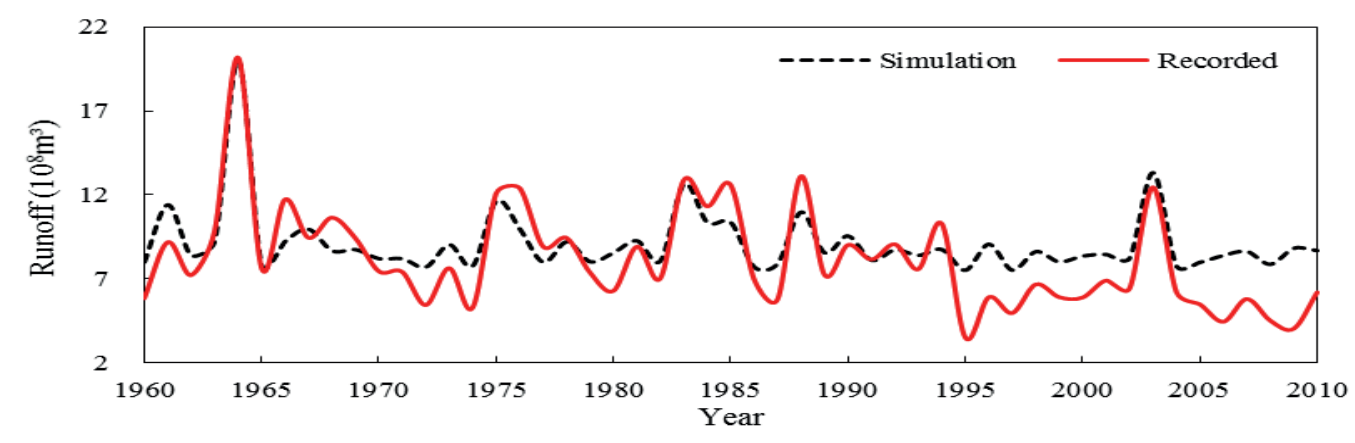

Fig. 4 Yearly series of observed and simulated runoff for 1960-2010 in BRB. 
Table 1 Contributions of climate change and human activities to the runoff change in BRB determined by the empirical model and climate elasticity.

\begin{tabular}{lllll}
\hline Periods & Empirical model & \multicolumn{2}{l}{ Climate elasticity } \\
& $C_{C}$ & $C_{H}$ & $C_{C}$ & $C_{H}$ \\
\hline $1970-1993$ & $83.42 \%$ & $16.58 \%$ & $70.84 \%$ & $29.16 \%$ \\
$1994-2010$ & $37.42 \%$ & $62.58 \%$ & $34.93 \%$ & $65.07 \%$ \\
\hline
\end{tabular}

4.3.2 Climate elasticity of runoff increment based on Budyko hypothesis Using equations (5)-(7), for the study area the precipitation and potential evaporation elasticity of runoff $\left(\varepsilon_{P}, \varepsilon_{P E}\right)$ were obtained as listed in Table 2 . The contribution rate from climate change and human activities to runoff increment (Table 1) can be separated based on equation (7). The contributions from climate change were $70.84 \%$ and $34.93 \%$ and from human activities were $29.16 \%$ and $65.07 \%$, respectively, for the periods of 1970-1994 and 1995-2010.

Table 2 The parameters used in equation (5) and (6).

\begin{tabular}{llllclll}
\hline Parameter & $\rho_{Q, P-P E}$ & $\rho_{Q, P E-P}$ & $C V_{Q}$ & $C V_{P}$ & $C V_{P E}$ & $\varepsilon_{P}$ & $\varepsilon_{P E}$ \\
\hline Value & 0.60 & -0.41 & 0.39 & 0.19 & 0.07 & 1.21 & -2.36 \\
\hline
\end{tabular}

\section{DISCUSSION}

According to the comprehensive analysis of the variation of water in the Loess Plateau, regional water conservation measures plays a dominant role on runoff reduction (Zhang et al. 2007; Wang et al. 2007). Runoff in the Beiluohe River basin (BRB) showed a trend of reduction, which had a close relationship with large-scale soil erosion control begun in 1970. According to statistics, by the end of 1996, in BRB, the cumulative area of terrace, forest, grass, and dam had reached $2731.87 \mathrm{~km}^{2}$. There were 78 reservoirs, with a total capacity of 234 million $\mathrm{m}^{3}$. The implementation of water conservation and water conservancy construction in BRB runoff reduction plays a key role (Liu et al., 2001).

\section{CONCLUSIONS}

For the Beiluohe River basin, two methods were applied to assess the contribution rate of climate change and human activities, and the results obtained were similar. The contribution rate of human activities obtained by the decomposition method, for the periods of 1970-1994 and 1995-2010, were higher than by the other methods. The reason is that the data reconstructed by hydrographic office comprehensively considered all human activities such as land cover changes, water use and water conservancy projects and so on.

The change points of runoff occurred in 1969 and 1994, for precipitation occurred in 1964 and 1985, and for PE in 1993. The relationship of runoff and precipitation, has begun to weaken since 1993, which was mainly caused by human activities.

Climate changes were the dominant factor inducing runoff decline in 1970-1994 compared with that in 1960-1969. And for the period 1995-2010, human activities played a critical role impacting the runoff. In 1970-1994, the contribution rate of climate change to runoff was around $70.84-83.42 \%$, and from human activities was $16.58-29.16 \%$. In 1995-2010, the contribution rates from climate change and human activities were around $34.93-37.42 \%$ and $62.58-65.07 \%$, respectively.

\section{REFERENCES}

Bao, Z.X., et al. (2012) Attribution for decreasing streamflow of the Haihe River basin, northern China: Climate variability or human activities? Journal of Hydrology 460(16), 117-129.

Dong, Q.G., et al. (2014) Analysis of runoff variation characteristics of Beiluo River. Yellow River 36(17), $20-24$.

Du, J. and Shi, C.X. (2012) Effects of climatic factors and human activities on runoff of the Weihe River in recent decades. Quaternary International 282(7), 58-65. 
Li, L.J., et al. (2007) Assessing the impact of climate variability and human activities on streamflow from the Wuding River basin in China. Hydrol. Processes 21, 3485-3491.

Liquete, C., et al. (2009) Sediment discharge of the rivers of Catalonia, NE Spain, and the influence of human impacts. Journal of Hydrology 366(5), 76-88.

Liu, B., et al. (2007) Influence of human activities on control of soil and water loss in Beiluo River basin. Yellow River 16(23), $16-19$.

Liu, Q. and Cui, B.S. (2011) Impacts of climate change/variability on the streamflow in the Yellow River Basin, China. Ecological Modelling 222(3), 268-274

Milliman, J.D., et al. (2008) Climatic and anthropogenic factors affecting river discharge to the global ocean, 1951-2000. Global and Planetary Change 62 (3-4), 187-194.

Parks, B.and Madison, R.J. (1985) Estimation of selected flow and water-quality characteristics of Alaskan Streams (No. WRI84-4247). United States Geological Survey.

Wang, L.N. (2007) Temporal spatial characteristics of runoff and sediment in Coarse Sand Source Regions of the Loess Plateau. Research Center of Soil and Water Conservation and Ecological Environment.

Zhang, J.Y., et al. (2007) Impact of Climate Change on Hydrology and Water Resources. Science Press, Beijing.

Zhang, X.P. (2007) Responses of streamflow to land use/cover change in HeLong region, the middle reaches of Yellow River, China. Research Center of Soil and Water Conservation and Ecological Environment. 